Reingard Spannring, Karin Schachinger, Gabriela Kompatscher, Alejandro Boucabeille (Hg.)

Disziplinierte Tiere? 
Lynne Chisholm und Otta Wenskus gewidmet, die uns ermutigt haben, unseren eigenen wissenschaftlichen Weg zu gehen.

Reingard und Gabriela

\section{Reingard Spannring}

Institut für Erziehungswissenschaft, Universität Innsbruck

Gabriela Kompatscher

Institut für Sprachen und Literaturen, Universität Innsbruck

Karin Schachinger

Studentin im MA-Programm »Gender, Culture and Social Change«, Universität Innsbruck

Alejandro Boucabeille

Dissertant am Institut für Zeitgeschichte, Universität Innsbruck 
Reingard Spannring, Karin Schachinger, Gabriela Kompatscher, Alejandro Boucabeille (Hg.)

\section{Disziplinierte Tiere?}

Perspektiven der Human-Animal Studies

für die wissenschaftlichen Disziplinen 
Diese Publikation wurde mit finanzieller Unterstützung aus den Fördermitteln des Vizerektorats für Forschung der Leopold-Franzens-Universität Innsbruck, des Dekanats der Bildungswissenschaftlichen Fakultät der Universität Innsbruck, des Forschungszentrums Bildung-Generation-Lebenslauf sowie United Creatures gedruckt.
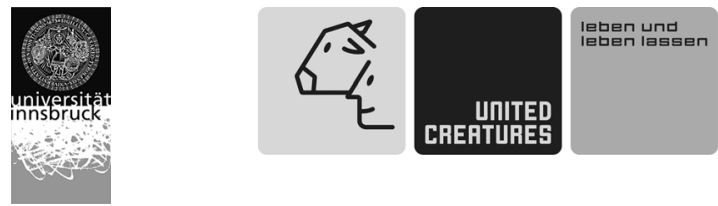

\section{Bibliografische Information der Deutschen Nationalbibliothek}

Die Deutsche Nationalbibliothek verzeichnet diese Publikation in der Deutschen Nationalbibliografie; detaillierte bibliografische Daten sind im Internet über http:// dnb.d-nb.de abrufbar.

\section{() 2015 transcript Verlag, Bielefeld}

Die Verwertung der Texte und Bilder ist ohne Zustimmung des Verlages urheberrechtswidrig und strafbar. Das gilt auch für Vervielfältigungen, Übersetzungen, Mikroverfilmungen und für die Verarbeitung mit elektronischen Systemen.

Umschlaggestaltung: Kordula Röckenhaus, Bielefeld

Lektorat: Reingard Spannring, Gabriela Kompatscher, Karin Schachinger,

Alejandro Boucabeille

Korrektorat: Jan Wenke

Satz: Reingard Spannring, Gabriela Kompatscher, Karin Schachinger

Druck: Majuskel Medienproduktion GmbH, Wetzlar

Print-ISBN 978-3-8376-2518-9

PDF-ISBN 978-3-8394-25I8-3 